\title{
Ambiente de aprendizagem e Jogos de empresas: a percepção dos discentes
}

\section{Learning environment and Business games: the perception of the students}

\author{
Tatiani Schmitt \\ Anete Alberton \\ Marco Aurélio Butzke \\ Francine Simas Neves
}

O jogo de empresas é uma estratégia de ensino ativa que oportuniza aos discentes uma experiência vivencial mais próxima da realidade organizacional, o qual é desenvolvido em ambientes de aprendizagem. O objetivo da presente pesquisa é analisar a percepção dos discentes ao utilizar a estratégia de ensino jogos de empresas em um ambiente virtual de aprendizagem em duas universidades de Santa Catarina. A pesquisa é considerada mista, de abordagem quantitativa e qualitativa, com dados oriundos de 2 questionários e de 2 focus group aplicados com discentes de graduação e pós-graduação de duas universidades de Santa Catarina. $\mathrm{Na}$ análise dos dados foram utilizadas a estatística descritiva, a análise fatorial e a análise de conteúdo. Os resultados mostram que os discentes tiveram uma percepção positiva sobre o uso da estratégia de ensino Jogos de empresas e no ambiente de aprendizagem apontaram dificuldades ao utilizar a plataforma digital dos jogos. A principal contribuição é o fornecimento de subsídios aos docentes para aperfeiçoar o processo de ensino-aprendizagem, bem como um estímulo para docentes utilização de jogos de empresas e de outras estratégias de ensino em sala de aula, levando em consideração questões importantes para o sucesso na aplicação.

Palavras-chave: Ambiente de aprendizagem; Estratégias de ensino; Jogos de empresas; Gestão.

The business game is an active teaching strategy that gives the students an experience close to the organizational reality developed in learning environments. This research aims to analyze students' perceptions when using the strategy of teaching business games in a virtual learning environment at two universities in Santa Catarina. The research is considered mixed, with a quantitative and qualitative approach, with data from 2 questionnaires and two focus groups applied to undergraduate
Recebido em: 28/01/2021 Aprovado em: 26/05/2021

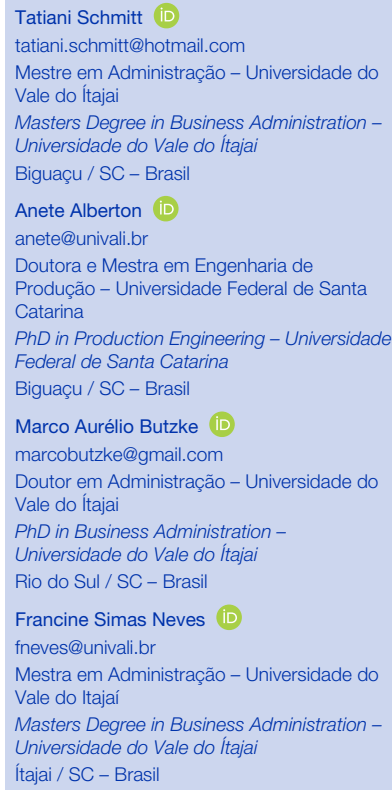

Masters Degree in Business Administration Universidade do Vale do Ítajai Ítajai / SC - Brasil 
and graduate students from two universities in Santa Catarina. In the data analysis, we used descriptive statistics, factor analysis, and content analysis. The results show that the students had a positive perception of using the Business Games teaching strategy and pointed out difficulties in the learning environment while using the digital games platform. The main contribution is providing subsidies to teachers to improve the teaching-learning process and a stimulus for teachers to use business games and other teaching strategies in the classroom, taking into account important issues for the application's success.

Keywords: Learning environment; Teaching strategies; Business games; Management.

\section{Introdução}

Mudanças no perfil dos discentes e a presença de novas tecnologias tem feito com que as estratégias de ensino ativas sejam, cada vez mais, adotadas pelos docentes em sala de aula, a fim de aproximar o discente da experiência real com o ambiente corporativo e propiciar o desenvolvimento de habilidades para lidar com as mudanças que ocorrem nesse meio. $O$ jogo de empresas, na concepção de Motta, Melo e Paixão (2012), é uma das estratégias que tem demonstrado crescente utilização pelas instituições de ensino superior no Brasil, especialmente nos cursos de graduação em Administração, com foco nos ambientes laborais (SILVA; SAUAIA, 2018). Uma vez que, essa área de estudo é uma das áreas que mais está sujeita a pressão na atual conjuntura, seja pelas mudanças profundas no mercado ou pela tecnologia em si (CARVALHO et al., 2020).

O jogo geralmente acontece numa plataforma computacional, por meio de um ambiente virtual ou um software, que permite ao discente a interação, mediada pelo docente, em um cenário corporativo. Com a adoção dessa estratégia, o docente colaborará com o processo de ensino, por meio da criação de um ambiente virtual de aprendizagem, o qual auxiliará os discentes no modo de simular as situações complexas que surgem no cotidiano das organizações (BUTZKE; ALBERTON, 2017). Dessa forma, com o uso de novas estratégias de ensino e de tecnologia na educação, o discente ficará frente a um ambiente virtual de aprendizagem com processo dinâmico que fomentará a sua reflexão (CALIARI; ZILBER; PEREZ, 2017). 
Os estudos sobre esta estratégia no âmbito nacional, em sua maioria, têm investigado o desenvolvimento de simuladores e as dinâmicas de jogos em si (MRTVI et al., 2017). Motta, Melo e Paixão (2012) afirmam a necessidade de estudos mais aprofundados sobre a contribuição do jogo de empresas na formação dos discentes, a fim de fornecer subsídios para a reflexão sobre a utilização dessa estratégia na educação gerencial. Com isso, torna-se relevante estudar a percepção dos discentes diante da utilização de jogo de empresas como estratégia de ensino e ambiente de aprendizagem.

Neste sentido, o objetivo desta pesquisa é analisar a percepção dos discentes de graduação e pós-graduação, em gestão de duas universidades de Santa Catarina, ao utilizar a estratégia de ensino jogos de empresas em um ambiente virtual de aprendizagem.

\section{Fundamentação teórica}

Esta seção abordará os temas centrais que sustentam esta pesquisa - Jogos de empresas e Ambiente virtual de aprendizagem.

\section{JOGOS DE EMPRESAS}

No Brasil, os Jogos de Empresas começaram a ser difundidos a partir dos anos 1970 com o estudo de Tanabe (1973), um dos pioneiros desta metodologia no país, e ganhou força na década de 1980, quando mais pesquisadores começaram a contribuir com este campo acadêmico, inclusive o Programa de Pós-graduação em Engenharia de Produção da Universidade Federal de Santa Catarina (UFSC) foi criado com a finalidade de desenvolver jogos educacionais por seus integrantes, bem como tratar de pesquisas na área da Engenharia (LOPES, 2001). Os primeiros jogos eram modelos importados dos EUA e traduzidos para serem utilizados no Brasil (LOPES, 2001; SAUAIA; ZERRENNER, 2009). Desde então, essa estratégia de ensino ativa está presente em diversos cursos de graduação e pós-graduação de Administração e áreas afins no país.

O jogo de empresas é um método dinâmico que permite ao discente uma vivência real da prática das organizações, no qual aprende-se com a experiência, por 
meio de seus erros e acertos ao tomar as próprias decisões durante o ciclo do jogo. Caracterizados por representações virtuais de situações reais de negócios, os jogos permitem ao discente o gerenciamento de negócios em um ambiente livre de riscos (BUIL; CATALÁN; MARTÍNEZ, 2019). Zulfiqar et al. (2018) afirmaram que o discente pode aprender de maneira mais prática por meio dessa estratégia, considerando o jogo como um cenário da realidade, em que é possível provar distintas estratégias e vivenciar circunstâncias específicas. Motta e Quintella (2012) enfatizam ainda que essa estratégia proporciona aos discentes uma experiência de aprendizagem significativa e recreativa.

Na concepção de Sauaia e Zerrenner (2009), o Jogo de Empresas proporciona a aprendizagem vivencial aos discentes, integrando as diversas áreas práticas presentes na matriz curricular, o qual possibilita um ambiente prático para utilização das teorias abordadas em classe na tomada de decisão. Essa estratégia de ensino oportuniza ao discente o aprendizado de habilidades de negócios enquanto gerenciam uma empresa em equipe (Löffler et al., 2018).

Liao, Huang e Wang (2015) incentivam a utilização dos jogos por cursos na área da gestão para apresentar várias situações complicadas do negócio aos discentes, a fim de estabelecer uma ponte entre a teoria e a prática e diminuir o gap existente, viabilizando aos discentes o envolvimento ativo no processo de aprendizagem (BERGAMASCHI FILHO; ALBURQUERQUE, 2010; SIGNORI et al., 2018). Por intermédio dos jogos, os discentes podem criar e gerir diversos negócios, encarar seus desafios e obstáculos em um ambiente sem risco e por fim, alcançar a recompensa (ZULFIQAR et al., 2018).

Na percepção dos discentes e coordenadores, o trabalho em equipe e a integração de conteúdo de diversas áreas do conhecimento são aspectos benéficos na adoção de Jogos de Empresas em sala de aula (MOTTA; QUINTELLA, 2012; NEVES; ALBERTON, 2017). No estudo de Chang et al. (2014), o entendimento sobre a complexidade de administrar uma empresa, bem como a integração do conhecimento foram percebidos pelos discentes como elementos favoráveis ao uso dessa estratégia. Gundala e Singh (2016) afirmam que essa estratégia oportuniza ao discente a prática do conhecimento adquirido na teoria e a visão integral do funcionamento de uma empresa. Inclusive, Oliveira e Melo (2020) contataram, em um quase-experimento, uma maior assimilação do conhecimento por parte dos alunos 
que receberam todo o conteúdo teórico antes de participarem do jogo, em relação a parte que recebeu durante o jogo. Como apontado nos estudos anteriores, os Jogos de Empresas oportunizam diversos benefícios para o processo de aprendizagem do discente, o que torna essa estratégia relevante para uma formação superior significativa ao indivíduo.

Nesse sentido, esta pesquisa identifica a percepção do discente no que tange aos fatores facilitadores de aprendizado na utilização dessa estratégia de ensino, sendo essa uma das proposições deste estudo. Como subsídios a delimitação dos fatores facilitadores para o aprendizado (Skill Acquisition) destacam-se os estudos de Miles, Biggs e Schubert (1986), Jennings (2002), Chang (2003), Chang et al. (2005), Adobor e Daneshfar (2006), Neves e Alberton (2017), Butzke e Alberton (2017) e Farashahi e Tajeddin (2018) os quais são exibidos na Figura 1.

Os estudos da Figura 1 adotaram como base o modelo de instrumento de pesquisa skill acquisition questionnaire criado por Miles, Biggs e Schubert (1986) com 28 itens e adaptado posteriormente por Jennings (2002) para 22 e posteriormente 20 itens, com a finalidade de identificar a percepção dos discentes quanto à aquisição de habilidades quando utilizam Jogos de Empresas e casos para ensino. No Brasil, esse instrumento foi adaptado por Pereira (2012), que analisou a opinião dos discentes quanto ao uso do método do Caso para Ensino. Posteriormente, foi utilizado por Butzke e Alberton (2017) e Neves e Alberton (2017), que o adequaram para Jogos de Empresas.

Figura 1 Estudos sobre fatores facilitadores de aprendizagem ao utilizar Jogos de Empresas

\begin{tabular}{|c|c|c|c|}
\hline Autores & $\begin{array}{l}\text { Proposição do } \\
\text { estudo }\end{array}$ & Metodologia & Resultados \\
\hline $\begin{array}{l}\text { Miles, } \\
\text { Biggs e } \\
\text { Schubert } \\
(1986)\end{array}$ & $\begin{array}{l}\text { Comparar a percep- } \\
\text { ção dos discentes na } \\
\text { aquisição de habilida- } \\
\text { des por meio da utili- } \\
\text { zação de casos para } \\
\text { ensino e simulações } \\
\text { de negócios. }\end{array}$ & $\begin{array}{l}\text { - Estudo quantita- } \\
\text { tivo. } \\
\text { - } 64 \text { discentes do } \\
\text { curso de Política } \\
\text { Comercial (EUA). }\end{array}$ & $\begin{array}{l}\text { - Os discentes perceberam } \\
\text { ambas as estratégias como } \\
\text { viáveis e valiosas na aquisição } \\
\text { de habilidades. } \\
\text { - Casos para ensino foram per- } \\
\text { cebidos como superiores as } \\
\text { simulações. }\end{array}$ \\
\hline
\end{tabular}




\begin{tabular}{|c|c|c|c|}
\hline $\begin{array}{l}\text { Jennings } \\
(2002)\end{array}$ & $\begin{array}{l}\text { Comparar a percep- } \\
\text { ção dos discentes } \\
\text { ao utilizar casos para } \\
\text { ensino, simulações de } \\
\text { negócios e projetos } \\
\text { de consultoria. }\end{array}$ & $\begin{array}{l}\text { - Estudo quantitativo. • } \\
\text { - } 46 \text { discentes do } \\
\text { curso de mestrado } \\
\text { em Gestão Estraté- } \\
\text { gica (Reino Unido). }\end{array}$ & $\begin{array}{l}\text { As três estratégias apresen- } \\
\text { tam eficácia, porém os casos } \\
\text { para ensino foram considera- } \\
\text { dos superiores. }\end{array}$ \\
\hline $\begin{array}{l}\text { Chang } \\
(2003)\end{array}$ & $\begin{array}{l}\text { Comparar a percep- } \\
\text { ção dos discentes } \\
\text { ao utilizar casos para } \\
\text { ensino, simulações de } \\
\text { negócios e projetos } \\
\text { de consultoria. }\end{array}$ & $\begin{array}{l}\text { - Estudo quantitativo. } \\
\text { - } 28 \text { discentes do } \\
\text { curso de mestrado } \\
\text { em Gestão Estraté- } \\
\text { gica (China). }\end{array}$ & $\begin{array}{l}\text { - A utilização de diversas es- } \\
\text { tratégias de ensino propicia } \\
\text { o desenvolvimento de mais } \\
\text { habilidades. } \\
\text { A simulação de negócios tem } \\
\text { maior aceitação. }\end{array}$ \\
\hline $\begin{array}{l}\text { Chang et } \\
\text { al. (2005) }\end{array}$ & $\begin{array}{l}\text { Comparar a percep- } \\
\text { ção dos discentes } \\
\text { ao utilizar casos para } \\
\text { ensino, simulações de } \\
\text { negócios e projetos de } \\
\text { consultoria. }\end{array}$ & $\begin{array}{l}\text { - Estudo quantitativo. } \\
\text { - } 36 \text { discentes do } \\
\text { curso de mestrado } \\
\text { em Gestão Estraté- } \\
\text { gica (China). }\end{array}$ & $\begin{array}{l}\text { A estratégia simulação de } \\
\text { negócios apresenta maior } \\
\text { significância por fornece mais } \\
\text { aprendizagem ao discente. }\end{array}$ \\
\hline $\begin{array}{l}\text { Adobor e } \\
\text { Danesh- } \\
\text { far (2006) }\end{array}$ & $\begin{array}{l}\text { Aumentar a compre- } \\
\text { ensão dos fatores que } \\
\text { promovem o uso efi- } \\
\text { caz de simulações na } \\
\text { educação gerencial. }\end{array}$ & $\begin{array}{l}\text { - Estudo quantita- } \\
\text { tivo. } \\
\text { - } 49 \text { discentes do } \\
\text { curso de Gestão } \\
\text { Estratégica (EUA). }\end{array}$ & $\begin{array}{l}\text { A aprendizagem associou-se } \\
\text { positivamente ao realismo da } \\
\text { simulação, a facilidade de uso } \\
\text { e ao conflito de tarefas. Mas, } \\
\text { negativamente ao conflito } \\
\text { emocional. } \\
\text { A facilidade de uso e o conflito } \\
\text { de tarefas afetou positiva- } \\
\text { mente o desempenho, porém } \\
\text { o conflito emocional o afetou } \\
\text { negativamente. }\end{array}$ \\
\hline $\begin{array}{l}\text { Butzke e } \\
\text { Alberton } \\
(2017)\end{array}$ & $\begin{array}{l}\text { Analisar a relação } \\
\text { entre os estilos de } \\
\text { aprendizagem e a } \\
\text { percepção dos dis- } \\
\text { centes na aplicação } \\
\text { de jogos de empresas } \\
\text { e ambiente de apren- } \\
\text { dizagem. }\end{array}$ & $\begin{array}{l}\text { - Estudo quantita- } \\
\text { tivo. } \\
\text { - } 143 \text { discentes dos } \\
\text { cursos de gradu- } \\
\text { ação de Adminis- } \\
\text { tração, Comércio } \\
\text { Exterior e Enge- } \\
\text { nharia de Produção } \\
\text { (Brasil). }\end{array}$ & $\begin{array}{l}\text { Os discentes reconheceram a } \\
\text { contribuição do jogo de em- } \\
\text { presas para melhorar o apren- } \\
\text { dizado. Evidenciaram alguns } \\
\text { aspectos: integrando a apren- } \\
\text { dizagem em diversas áreas; } \\
\text { proporcionando novos conhe- } \\
\text { cimentos sobre a operação } \\
\text { da empresa; aumentando a } \\
\text { capacidade de identificar pro- } \\
\text { blemas gerenciais; ajudando a } \\
\text { conhecer as atividades perti- } \\
\text { nentes à prática profissional; e } \\
\text { estimulando a criatividade. }\end{array}$ \\
\hline
\end{tabular}




\begin{tabular}{|c|c|c|c|}
\hline $\begin{array}{l}\text { Neves e } \\
\text { Alberton } \\
(2017)\end{array}$ & $\begin{array}{l}\text { Analisar a percepção } \\
\text { dos } \\
\text { alunos da área de } \\
\text { gestão ao utilizar } \\
\text { jogos de empresas } \\
\text { baseados em simu- } \\
\text { lação }\end{array}$ & $\begin{array}{l}\text { - Estudo quantitativo. } \\
\text { - } 210 \text { discentes dos } \\
\text { cursos de gradua- } \\
\text { ção de e pós-gra- } \\
\text { duação da Univer- } \\
\text { sidade do vale do } \\
\text { Itajaí (Brasil). }\end{array}$ & $\begin{array}{l}\text { Os jogos de empresas na } \\
\text { percepção dos discentes fa- } \\
\text { vorece o aprendizado, com } \\
\text { destaque em alguns aspectos: } \\
\text { integrando a aprendizagem } \\
\text { em diversas áreas, ampliando } \\
\text { a visão sobre o funcionamento } \\
\text { de uma empresa; e aumentan- } \\
\text { do a capacidade do discente } \\
\text { de se comunicar com os seus } \\
\text { colegas. }\end{array}$ \\
\hline $\begin{array}{l}\text { Farashahi } \\
\text { e Tajed- } \\
\text { din (2018) }\end{array}$ & $\begin{array}{l}\text { Comparar e testar a } \\
\text { eficácia dos métodos } \\
\text { palestra, caso para } \\
\text { ensino e simulação }\end{array}$ & $\begin{array}{l}\text { - Estudo quantitativo. } \\
\text { - } 29 \text { discentes de } \\
\text { graduação e MBA } \\
\text { de uma escola de } \\
\text { negócios no Ca- } \\
\text { nadá. }\end{array}$ & $\begin{array}{l}\text { Na percepção dos discentes } \\
\text { de graduação e pós-gradu- } \\
\text { ação, os jogos de empresas } \\
\text { são considerados como méto- } \\
\text { do de ensino mais eficaz. } \\
\text { Também foi percebido que os } \\
\text { discentes de MBA e gradu- } \\
\text { ação possuem percepções } \\
\text { distintas, pois os discentes de } \\
\text { MBA percebem o método de } \\
\text { estudo de caso mais eficaz no } \\
\text { desenvolvimento de suas ha- } \\
\text { bilidades interpessoais e os da } \\
\text { graduação percebem a pales- } \\
\text { tra (aula) como mais eficaz. }\end{array}$ \\
\hline
\end{tabular}

Nota: Autoria própria a partir da revisão de literatura (2020)

No estudo de Neves e Alberton (2017) foram verificados quais os fatores que favorecem o aprendizado do discente com o uso de jogos, e três tópicos se destacaram: (1) integrando a aprendizagem em diversas áreas; (2) ampliando a visão sobre o funcionamento de uma empresa; e (3) aumentando a capacidade do discente de se comunicar com os seus colegas. Butzke e Alberton (2017) também examinaram os facilitadores do aprendizado, porém esses constataram cinco aspectos significativos: (1) integrando a aprendizagem em diversas áreas; (2) proporcionando novos conhecimentos sobre a operação da empresa; (3) aumentando a capacidade de identificar problemas gerenciais; (4) ajudando a conhecer as atividades pertinentes à prática profissional; e (5) estimulando a criatividade. $\mathrm{O}$ aspecto 1 (integrando a aprendizagem em diversas áreas) obteve bons indicadores na maioria dos estudos, 
especialmente em Chang (2003), Chang et al. (2005), Neves e Alberton (2017) e Butzke e Alberton (2017); enquanto aspecto 3 (aumentando a capacidade de identificar problemas gerenciais) teve destaque com bons resultados apenas nos estudos de Miles, Biggs e Schubert (1986) e de Butzke e Alberton (2017).

\section{AMBIENTE VIRTUAL DE APRENDIZAGEM}

A estratégia de ensino Jogos de Empresas geralmente ocorre em uma plataforma computacional, por intermédio de um ambiente virtual ou um software, que permite ao discente a interação, mediada pelo docente, em um cenário corporativo. Ao adotar esse método, o docente colaborará com o processo de ensino, por meio da criação de um ambiente virtual de aprendizagem, o qual ajudará os discentes no modo de simular as situações complexas que surgem no cotidiano das organizações (BUTZKE; ALBERTON, 2017). Na área da Administração, et al. (2012) alegam que, além dos Jogos de Empresas, diversas estratégias são beneficiadas pelo ambiente de aprendizagem graças à possibilidade que os docentes e discentes têm, entre si, de trocar experiências e vivenciar situações de negócios efetivos.

O Ambiente Virtual de Aprendizagem, conhecido também como AVA, é conceituado como um sistema de informação e comunicação (software) que possui ferramentas educacionais, por meio da web, capazes de mensurar a evolução do discente (CARVALHO NETO; TAKAOKA, 2010; MULBERT; BRAZ JUNIOR, 2016). Caliari, Zilber e Perez (2017) complementam que esses ambientes possibilitam o desenvolvimento dos discentes de acordo com o seu tempo, espaço e ritmo.

O AVA está presente nos cursos presenciais, semipresenciais e a distância, com instrumentos e funcionalidades capazes de auxiliar no processo de ensino e aprendizagem (RAMOS; SILVA; CARVALHO, 2013). Afinal, cada vez mais os discentes apresentam aptidões tecnológicas, o que possibilita a utilização da web como forma de incrementar a educação no âmbito acadêmico (MONDINI et al, 2016). Com a utilização de ferramentas digitais, as atividades educacionais se tornam mais interessantes, criativas e de fácil acesso (BHATTARAl; MAHARJAM, 2020).

Além disso, o uso desse ambiente possibilita ao docente a expansão de seu papel no processo de aprendizado, quando passa de um mero informante, o qual apresenta somente o conteúdo, para um orientador de aprendizagem, o que o torna responsável por gerir a comunicação e a pesquisa dos discentes dentro e fora 
do ambiente de sala de aula (CARVALHO NETO; TAKAOKA, 2009). O ambiente de aprendizagem virtual está transformando a prática de ensino tradicional com a tecnologia e a inovação (BHATTARAl; MAHARJAM, 2020).

No ensino presencial, os AVA são utilizados pelos docentes como ambiente virtual de apoio, no qual disponibilizam funções online para ampliar o ensino em sala de aula (PEREIRA; SCHMITT; DIAS, 2007; CARVALHO NETO; TAKAOKA, 2009; CALIARI; ZILBER; PEREZ, 2017). No entanto, Pereira, Schmitt e Dias (2007) alegam que independente da modalidade adotada pelo curso, é importante estar atento ao selecionar as funcionalidades que serão ofertadas pela web, devendo levar em consideração as necessidades do público-alvo e da proposta pedagógica determinada pela instituição de ensino. Nesse sentindo, a instituição de ensino e o docente devem trabalhar juntos para oferecer um ambiente virtual de aprendizagem de manuseio simples e propício ao processo de ensino e aprendizagem.

Com relação às pesquisas que verificam a percepção dos indivíduos no uso do ambiente virtual de aprendizagem, Pereira, Oliveira e Momo (2013) e Teixeira, Stefano e Campos (2015) verificaram como os discentes percebem os fatores que influenciam na capacitação a distância oferecida em um AVA. Pereira et al. (2013) apontaram que a dimensão eficiência e confiabilidade tem maior proporção sobre a qualidade do AVA na percepção dos discentes e Teixeira et al. (2015), ao analisarem a percepção de funcionários de uma instituição financeira em relação ao AVA em uma Universidade Corporativa, constataram um elevado grau de aceitação nos aspectos de facilidade de interação, absorção de novos conhecimentos, utilização das ferramentas, habilidades no uso do AVA e aplicabilidade dos conhecimentos obtidos. Esses autores reconhecem o ambiente como propício também para a educação profissional.

Os estudos de Seddon e Kiew (1996), Carvalho Neto e Takaoka (2010) e Mondini et al. (2016) trataram da dimensão qualidade no AVA. Em seus estudos, Carvalho Neto e Takaoka (2010) utilizaram o Modelo de Sucesso de Sistemas de Informação (IS Success Model - IS) de DeLone e McLean (2003). Ao analisar as relações diretas existentes entre as dimensões, os autores constaram a inexistência de relação entre a qualidade da informação e a qualidade do sistema, enquanto as demais relações foram estatisticamente significantes. Seddon e Kiew (1996) abordaram também, em suas pesquisas, o modelo de DeLone e McLean, demostrando 
que as dimensões qualidade da informação, qualidade do sistema e utilidade representam $70 \%$ da satisfação dos usuários do sistema, assim como Mondini et al. (2016), que confirmaram a influência das dimensões de qualidade da informação e qualidade do sistema na satisfação dos usuários e seus benefícios percebidos.

Em contrapartida, os estudos de Ferreira et al. (2013), Ramos et al. (2013), Freitas et al. (2015), Pereira, Ramos e Chagas (2015), Butzke e Alberton (2017) e Huang et al. (2020) se embasaram no Modelo de Aceitação da Tecnologia (Theory Acceptance Model - TAM) desenvolvido por Davis (1989). Esse modelo procura esclarecer o motivo pelo qual o indivíduo aceita ou rejeita a utilização de determinada tecnologia, nesse caso o ambiente virtual de aprendizagem, independentemente de sua obrigatoriedade (PEREIRA et al., 2015; YAKUBU; MUHAMMADOU, 2020). Os autores alegam ainda que os modelos TAM e IS são os mais adotados na literatura, com aceitação satisfatória.

O Modelo de Aceitação da Tecnologia (Theory Acceptance Model - TAM), desenvolvido por Davis (1989), é formado por dois construtos: facilidade de uso e utilidade percebida. Posteriormente, Venkatesh e Davis (2000) complementaram o modelo com construtos relativos ao processo de influência social e de instrumental cognitivo, surgindo o TAM2. Porém, o modelo TAM ainda tem sido o mais bem aceito e o mais adotado nas pesquisas de âmbito nacional. Outro modelo que tem recebido destaque nos estudos nacionais é o de Sucesso de Sistemas de Informação (IS Success Model - IS) desenvolvido por DeLone e McLean (2003), o qual é constituído de cinco dimensões: qualidade da informação, qualidade do sistema, satisfação, uso e benefícios, a fim de mensurar a satisfação dos indivíduos usuários de um sistema web.

A pesquisa de Ramos et al. (2013) destaca que a utilização do AVA aumenta conforme os discentes consideram a dimensão utilidade percebida, pois a mesma impacta positivamente no seu uso, logo, com o aumento do desempenho dos discentes, mais intensa é a utilização do AVA. Freitas et al. (2015) concluíram que as dimensões utilidade, facilidade de uso e atitude são relevantes preditivos para quem possui a ideia de utilizar o AVA. No estudo de Butzke e Alberton (2017), a dimensão qualidade da informação obteve os melhores índices de concordância, seguida da dimensão utilidade percebida e por último a dimensão facilidade de uso que teve a menor pontuação, devido à dificuldade que é exposta nos Jogos de Empresas. $\mathrm{O}$ 
estudo de Huang et al. (2020) descobriram que os discentes são mais propensos a utilizar a tecnologias móveis na aprendizagem quando consideram elas úteis, pois seus resultados mostram que utilidade percebida influenciou significativamente na intenção comportamental.

Vale ressaltar que Ramos et al. (2013), Pereira et al. (2015), Butzke e Alberton (2017) utilizaram ainda a dimensão qualidade da informação, o qual pertence ao modelo de DeLone e McLean (2003), além de usufruírem do modelo de TAM. Os autores Ramos et al. (2013) comprovaram a influência positiva que a percepção da qualidade da informação desempenha sobre a utilidade percebida pelo indivíduo. Em seu estudo, Pereira et al. (2015) constatou forte associação entre as dimensões do modelo TAM com a qualidade da informação (SI) corroborando a pesquisa de Ramos et al. (2013).

Tanto os jogos de empresas como o ambiente virtual de aprendizagem têm proporcionado um contexto propício a erros e falhas dos discentes durante a realização de suas atividades, ao possibilitar que assumam riscos e experimentam novas práticas, favorecendo a sua aprendizagem experiencial e ativa (SILVA, 2016; CALVO; REIO, 2018). Diante disso, o discente é considerado um membro ativo do seu processo de aprendizagem, o que torna relevante compreender e capturar o seu entendimento sobre o uso da estratégia de ensino jogos de empresas em um ambiente virtual de aprendizagem. Uma vez que as instituições de ensino têm, cada vez mais, incentivado a sua adoção, e os estudos empíricos que abordam a educação empresarial são escassos na área de gestão segundo Lin, Huang e Ko (2020).

\section{Procedimentos metodológicos}

Esta pesquisa é considerada mista com abordagem quantitativa e qualitativa, a qual engloba coleta e análise dos dados de duas maneiras distintas na pesquisa (CRESWELL, 2007), para analisar a percepção dos discentes de graduação e pós-graduação, em gestão de duas universidades de Santa Catarina, ao utilizar a estratégia de ensino jogos de empresas em um ambiente virtual de aprendizagem. 
Portanto, a pesquisa é considerada de abordagem mista com procedimentos sequenciais, segundo Creswell (2007), visto que primeiro foi realizado uma pesquisa de abordagem quantitativa, mediante um levantamento (survey) com a aplicação de questionários aos discentes que utilizaram os jogos de empresas e posteriormente a parte de abordagem qualitativa por meio de focus group, o qual foi realizado ao término da aplicação do questionário.

A amostra é composta por 177 discentes dos cursos de graduação (Administração, Comercio Exterior, Logística, Gestão Portuária) e de pós-graduação (Gestão Tributária) de duas universidades de Santa Catarina que utilizaram a estratégia de ensino ativa Jogos de empresas em um ambiente virtual de aprendizagem. Inicialmente, os discentes utilizaram o simulador do Jogos de empresas em suas respectivas disciplinas, acompanhados pelos docentes responsáveis, nas quais vivenciaram a dinâmica dessa estratégia de ensino. Após um período de utilização da estratégia, foram aplicados os instrumentos de coleta de dados.

Para a coleta de dados, foram aplicados primeiramente a survey com: o instrumento de Skill acquisition (Apêndice A) baseado em Butzke (2015), traduzido e adaptado de Miles, Biggs e Schubert (1986) e Jennings (2002); o questionário sobre Ambiente de Aprendizagem (Apêndice A) baseado em Ramos et al. (2013), traduzido e adaptado de Davis, (1989); Delone e Mclean (2003), e sobre prática reflexiva adaptado de Araújo (2014). A escala utilizada para mensuração nos instrumentos de Skill acquisition, Ambiente de Aprendizagem e Prática Reflexiva é a tipo Likert de 7 pontos, na qual se atribui valores de 1 (que equivale a ajuda pouco) a 7 (que representa ajuda muito). Além destes inventários, informações específicas sobre o participante foram incluídas.

Foram também realizados focus group com 2 turmas de graduação após a aplicação dos questionários, para complementar os resultados obtidos com a aplicação dos instrumentos sobre a percepção dos discentes ao utilizar o Jogos de empresas como estratégia de ensino e sobre o ambiente virtual de aprendizagem. Os dados foram gravados por intermédio de um gravador de áudio e em seguida, transcritos na íntegra, a fim de facilitar a análise das informações coletadas. A análise desses dados foi desenvolvida conforme o método de análise de conteúdo proposta por Bardin (2016). 
Quanto a análise quantitativa de dados, foi aplicada a análise descritiva e a análise fatorial, com o auxílio dos softwares Microsoft Excel $®$ e Software for Statistics and Data Science - STATA. Na análise descritiva das variáveis identificadas nos instrumentos, foram empregados a estatística descritiva com análises de frequências, impacto médio e área de impacto dos dados. Além disso, esses resultados são apresentados mediante os percentuais das áreas de impacto, os quais foram calculados com base em Pereira (2004). Para facilitar a compreensão das tabelas com a área de impacto, foram incluídas cores, nas quais verde representa maior concordância e vermelho se refere à menor concordância na percepção dos discentes pesquisados.

A análise fatorial foi utilizada para verificar a percepção dos discentes sobre a Skill acquisition, ambiente virtual de aprendizagem e a prática reflexiva nos jogos de empresas, a fim de apontar os fatores gerados a partir dos conjuntos de variáveis correlacionadas.

\section{Apresentação e análise dos resultados}

A Tabela 1 apresenta a percepção dos discentes, comparativamente aos resultados das pesquisas de Miles, Biggs e Schubert (1986), Jennings (2002), Chang (2003), Chang et al. (2005), Butzke (2015) e Neves e Alberton (2017) referentes à Skill Acquisition ao utilizar a estratégia de ensino Jogos de Empresas.

Em geral, observa-se que 16 das 30 variáveis avaliadas obtiveram concordância maior ou igual a 50\% na percepção dos discentes. Das 15 variáveis com melhor pontuação, se destaca a variável "Ajuda a integrar a aprendizagem em diversas áreas: Contabilidade, Finanças, Marketing etc." (SKA05: 60,80\%), única com área de impacto superior a 60\%. Esse resultado foi confirmado durante as entrevistas do Focus Group com a percepção de alguns participantes da graduação:

[...] ele interliga todas as áreas de como funciona uma empresa mesmo a gente tem que estar lidando com todos os designers foi estipulado [...] (Participante GC/2);

Eu acho que o jogo ajuda a observar outros pontos que antes agente não teria essa percepção sabe é que poderia influenciar a empresa [...] (Participante SL/2)

[...] fazendo na prática mesmo não sendo dono de empresa agente começa a enxergar com outros olhos a empresa onde a gente trabalha, como o RH, a parte financeira, e como tudo 
isso tem que estar funcionar para no final ter um resultado bom não adianta você focar numa área e prestar atenção só nela até porque o resto não funciona independente dela mesmo sendo coisa diferente. (Participante AF/2)

Os participantes compreenderam que há diversas áreas responsáveis pelo bom funcionamento da organização. Esse resultado da variável SKA05 corrobora os estudos de Chang et al. (2005), Butzke (2015) e Neves e Alberton (2017) que identificaram área de impacto, respectivamente de 75\%, 63\% e 62\%, mas difere do estudo de Miles, Biggs e Schubert (1986) que identificou área de 20\%. Os discentes da pós-graduação também apontaram essa variável (SKA05: 51,11\%) como pouco facilitadora do processo de aprendizagem. As demais variáveis mencionadas mantêm os escores entre 50\% e 60\% de concordância na área de impacto.

Outra variável enfatizada é a "Motiva o trabalho em equipe" (SKA21: 58,86\%), comentada também no Focus Group, em que os discentes concordaram que os Jogos de Empresas proporcionam a troca de ideias em grupo, como mostra os discursos mencionados a seguir:

[...] todas as decisões foram tomadas em consenso, pelo menos no nosso grupo tinha opiniões divergentes mais agente dialogava até chegar no consenso comum e tomar uma decisão eu acho que isso agregou bastante dialogo. (Participante MR/1)

[...] todo mundo tinha que entrar no acordo ne, então a gente teve as vezes que concordar um com o outro mais a gente tinha que chegar no consenso junto eu acho que isso ajudou bastante a ter esse censo de equipe, pensar num todo mesmo de empresa [...] a gente realmente teve que aprender a vivenciar isso assim. (Participante PM/2)

Isso demostra que os jogos auxiliam os discentes a trabalhar em equipes e a lidar com visões diferentes, entendendo que cada indivíduo parte de uma perspectiva, corroborando o estudo de Madkur, Mirtvi e Lopes (2008), Motta e Quintella (2012) e Neves e Alberton (2017) em que o trabalho em equipe é apontado como benéfico aos discentes. Além disso, Madkur, Mirtvi e Lopes (2008) alegam que os discentes participam mais do processo decisório quando as equipes formadas são heterogêneas. Entre os discentes da pós-graduação, essa variável (SKA21: $77,78 \%$ ) foi considerada a que mais facilita o processo de aprendizagem ao utilizar o Jogos de Empresas. 
Tabela 1 Comparativo dos estudos entre as áreas de impacto das Skill Acquisition

\begin{tabular}{|c|c|c|c|c|c|c|c|}
\hline Variáveis & $\begin{array}{l}\text { Miles, Biggs } \\
\text { e Schubert } \\
\text { (1986) }\end{array}$ & $\begin{array}{c}\text { Jennings } \\
(2002)\end{array}$ & $\begin{array}{l}\text { Chang } \\
(2003)\end{array}$ & $\begin{array}{l}\text { Chang } \\
\text { et al. } \\
(2005)\end{array}$ & $\begin{array}{l}\text { Butzke } \\
\text { (2015) }\end{array}$ & $\begin{array}{c}\text { Neves e } \\
\text { Alberton } \\
\text { (2017) }\end{array}$ & $\begin{array}{c}\text { Dados } \\
\text { da } \\
\text { Pesquisa }\end{array}$ \\
\hline SKA05 & $20,33 \%$ & $52,33 \%$ & $58,00 \%$ & $75,00 \%$ & $63,67 \%$ & $62,72 \%$ & $60,80 \%$ \\
\hline SKA30 & & & & & $64,00 \%$ & $52,67 \%$ & $59,66 \%$ \\
\hline SKA07 & & & & & $52,00 \%$ & $45,67 \%$ & $59,51 \%$ \\
\hline SKA21 & $1,67 \%$ & $34,67 \%$ & $19,00 \%$ & $31,67 \%$ & $51,67 \%$ & $43,67 \%$ & $58,86 \%$ \\
\hline SKA25 & $16,00 \%$ & $23,67 \%$ & $24,00 \%$ & $38,33 \%$ & $56,33 \%$ & $61,67 \%$ & $57,66 \%$ \\
\hline SKA2O & $20,67 \%$ & $18,00 \%$ & $31,00 \%$ & $43,33 \%$ & $51,33 \%$ & $38,00 \%$ & $57,39 \%$ \\
\hline SKA06 & $17,67 \%$ & $41,00 \%$ & $30,67 \%$ & $43,33 \%$ & $62,00 \%$ & $47,16 \%$ & $56,63 \%$ \\
\hline SKA23 & $6,67 \%$ & $42,67 \%$ & $34,33 \%$ & $50,00 \%$ & $58,00 \%$ & $51,93 \%$ & $56,25 \%$ \\
\hline SKA26 & $7,33 \%$ & $43,33 \%$ & $42,67 \%$ & $56,67 \%$ & $53,33 \%$ & $50,54 \%$ & $56,25 \%$ \\
\hline SKA18 & $17,33 \%$ & $51,33 \%$ & $41,00 \%$ & $46,67 \%$ & $49,00 \%$ & $56,00 \%$ & $55,68 \%$ \\
\hline SKA27 & & & & & $62,33 \%$ & $54,33 \%$ & $55,68 \%$ \\
\hline SKA16 & & $52,67 \%$ & $56,67 \%$ & $66,67 \%$ & $50,67 \%$ & $46,89 \%$ & $55,43 \%$ \\
\hline SKA15 & $6,33 \%$ & $38,33 \%$ & $33,33 \%$ & $41,67 \%$ & $58,00 \%$ & $47,93 \%$ & $54,29 \%$ \\
\hline SKA19 & $13,00 \%$ & $26,33 \%$ & $41,00 \%$ & $50,00 \%$ & $50,67 \%$ & $52,33 \%$ & $53,79 \%$ \\
\hline SKA01 & $12,00 \%$ & $44,33 \%$ & $46,00 \%$ & $50,00 \%$ & $63,67 \%$ & $52,71 \%$ & $53,48 \%$ \\
\hline SKA08 & $15,00 \%$ & $43,33 \%$ & $46,67 \%$ & $51,67 \%$ & $54,33 \%$ & $42,20 \%$ & $51,22 \%$ \\
\hline SKA29 & $-23,67 \%$ & $19,33 \%$ & $4,33 \%$ & $23,33 \%$ & $64,00 \%$ & $48,46 \%$ & $49,81 \%$ \\
\hline SKA24 & $0,67 \%$ & $44,33 \%$ & $27,67 \%$ & $50,00 \%$ & $57,33 \%$ & $51,44 \%$ & $49,81 \%$ \\
\hline SKA11 & $23,33 \%$ & $42,00 \%$ & $46,00 \%$ & $51,67 \%$ & $56,33 \%$ & $46,35 \%$ & $48,30 \%$ \\
\hline SKA28 & $13,67 \%$ & $59,00 \%$ & $55,67 \%$ & $78,33 \%$ & $59,00 \%$ & $46,91 \%$ & $47,83 \%$ \\
\hline SKA12 & $19,33 \%$ & $38,33 \%$ & $39,00 \%$ & $51,67 \%$ & $58,33 \%$ & $43,62 \%$ & $45,79 \%$ \\
\hline SKA03 & & & & & $62,00 \%$ & $40,33 \%$ & $45,76 \%$ \\
\hline SKA10 & $19,33 \%$ & $38,33 \%$ & $27,67 \%$ & $41,67 \%$ & $57,33 \%$ & $41,86 \%$ & $44,44 \%$ \\
\hline SKA13 & & & & & $38,00 \%$ & $41,67 \%$ & $42,86 \%$ \\
\hline SKA02 & & & & & $57,00 \%$ & $42,33 \%$ & $40,87 \%$ \\
\hline SKA04 & & & & & $47,00 \%$ & $45,00 \%$ & $40,15 \%$ \\
\hline SKA09 & $27,67 \%$ & $42,00 \%$ & $50,67 \%$ & $72,00 \%$ & $37,00 \%$ & $33,32 \%$ & $39,77 \%$ \\
\hline SKA22 & $1,00 \%$ & $35,33 \%$ & $19,00 \%$ & $31,67 \%$ & $45,00 \%$ & $49,67 \%$ & $38,70 \%$ \\
\hline SKA14 & $7,33 \%$ & $37,67 \%$ & $34,33 \%$ & $45,00 \%$ & $40,00 \%$ & $28,70 \%$ & $35,42 \%$ \\
\hline SKA17 & & & & & $44,00 \%$ & $30,00 \%$ & $29,17 \%$ \\
\hline
\end{tabular}

Nota: Dados da pesquisa

As variáveis com piores pontuações na pesquisa obtiveram percentual na faixa entre $30 \%$ e $40 \%$, e destaca-se a variável "Aumenta a sua confiança na habilidade de trabalhar independentemente" (SKA14: 35,42\%), "Ajuda na resolução de conflitos" (SKA22: 38,70\%), "Auxilia a tomar decisões baseadas em informa- 
ções incompletas" (SKA09: 39,77\%). No entanto, a variável "Auxilia a lidar com a insegurança" (SKA17: 30,02\%) foi a única com escore inferior a 30\%, e corrobora o estudo de Neves e Alberton (2017) ao identificar essa variável como um dos aspectos que pouco facilitam a aprendizagem dos discentes ao utilizar Jogos de Empresas.

O baixo valor apresentado pela variável SKA14 foi comprovado durante o Focus Group:

Independente não porque a gente tinha que tomar as decisões todas em grupo né, então a gente não consegui trabalhar com a ideia independente e a questão de trabalhar em grupo foi boa porque a gente consegue discutir as estratégias [...] (Participante AN/1)

[...] acho que faltou um papel definido para cada gestor de um presidente, sentava todo mundo junto e fazia junto como um igual [...] (Participante GB/2)

Esses discursos refletem o aspecto mencionado anteriormente, de que os Jogos de Empresas têm contribuído para o desenvolvimento do exercício coletivo, evidenciando que essa estratégia desencoraja a atuação individual do discente.

$\mathrm{Na}$ Tabela 1 enfatiza-se a variável "Ajuda a integrar a aprendizagem em diversas áreas: Contabilidade, Finanças, Marketing etc." (SKA05: 60,80\%), a qual corrobora os estudos de Jennings (2002), Chang (2003), Chang et al. (2005), Butzke (2015) e Neves e Alberton (2017) que apontaram essa variável como um dos aspectos que mais facilitam a aprendizagem dos discentes ao usar a estratégia de ensino ativa Jogos de Empresas. Outras duas variáveis que obtiveram destaque nesta pesquisa foram: "Estimula a criatividade" (SKA30: 59,66\%) e "Favorece a análise de um problema sob diferentes pontos de vista, na discussão do grupo" (SKA07: $59,51 \%)$. Esses resultados apoiam o estudo de Butzke (2015) e Neves e Alberton (2017), porém essas variáveis não faziam parte dos estudos de Miles, Biggs e Schubert (1986), Jennings (2002), Chang (2003) e Chang et al. (2005).

Ao comparar as variáveis que possuem concordância maior ou igual a $50 \%$, esta pesquisa corrobora os estudos de Neves e Alberton (2017) em nove variáveis, Butzke (2015) em 15 variáveis, Chang et al. (2005) em sete variáveis, Chang (2003) em duas variáveis e Jennings (2002) em três variáveis. Nesse sentido, percebe-se que a variável SKA05, já mencionada anteriormente, se destacou em todos os estudos. 
Os resultados apresentados demonstram que os discentes consideram a estratégia de ensino Jogos de Empresas como facilitadora de aprendizagem, mantendo os impactos médios maiores que o ponto médio (4) da escala Likert aplicada nesta pesquisa e ainda corroborando os estudos de Miles, Biggs e Schubert (1986), Jennings (2002), Chang (2003) e Chang et al. (2005) que avaliaram as estratégias de ensino ativa como eficazes na aquisição de habilidades mediante a aprendizagem; e com os estudos de Butzke (2015) e Neves e Alberton (2017), que apontaram essa estratégia como facilitadora de aprendizagem.

$\mathrm{Na}$ Tabela 2 é demonstrada a percepção dos discentes acompanhado do resultado do estudo de Butzke (2015), que também se baseou em Davis (1989) e Ramos et al. (2013), referente ao ambiente virtual de aprendizagem na percepção dos discentes ao usar os Jogos de Empresas.

Ao examinar os resultados exibidos na Tabela 3, observa-se que nove das 20 variáveis avaliadas obtiveram concordância maior ou igual a 50\%. Das variáveis com melhor pontuação, destacam-se quatro que exibem área de impacto superior a 60\%: "O professor dá apoio contínuo no esclarecimento de dúvidas de conteúdo" (QAV14: 67,42\%), "O professor estimula constantemente o uso da plataforma" (QAV13: 66,29\%), "O professor fornece sistematicamente informações das atividades do Jogo de Empresas" (QAV15: 64,03\%), "Percebi a existência de visões diferentes sobre as decisões a serem tomadas durante o jogo" (QAV17: $62,90 \%)$. Esses resultados foram confirmados com o discurso dos participantes do Focus Group:

\footnotetext{
Todas as dúvidas que a gente teve o professor tirou [...] (Participante AN/1)

Eu acho que ele sempre deu suporte necessário quando a gente tinha dúvida [...] (Participante SL/2)

Eu percebi que conforme foram surgindo as jogadas, ele (professor) ia avançando mais informações isso estimulava a gente a querer saber mais sobre como funcionava a plataforma no caso ele deu a instrução pra gente, mas ele lançava essas informações pra nos estimular a ter mais criatividade a gente ter a nossa própria decisão não tomar uma decisão por ele [...] (Participante KT/2)
}

Ao observar o discurso dos discentes, é notável a atenção que o docente tem em esclarecer as dúvidas, mas de modo dinâmico, para auxiliar os discentes com o seu processo de aprendizado ao longo da estratégia Jogos de Empresas. 
Tabela 2 Comparativo dos estudos entre as áreas de impacto do ambiente virtual de aprendizagem

\section{Variáveis}

QAV14 O professor dá apoio continuo no esclarecimento de dúvidas de conteúdo

QAV13 O professor estimula constantemente o uso da plataforma

QAV15 O professor fornece sistematicamente informações das atividades do jogo de empresas

QAV17 Percebi a existência de visões diferentes sobre as decisões a serem tomadas durante o jogo

QAV12 As instruções fornecidas durante a aplicação do Jogo de Empresas eram atualizadas

QAV20 Ao expor a minha decisão, percebi que poderia mudar o meu posicionamento de forma a melhorá-lo

QAV16 Percebi oportunidades de alterar a minha visão sobre as decisões a serem tomadas durante o jogo

Percebi que a minha decisão poderia ter impactos que não havia

QAV19 percebido, e por isso, alterei a minha visão sobre as decisões a serem tomadas durante o jogo

Compreendi que minhas experiências poderiam favorecer o

QAV18 entendimento sobre o problema e melhorar as decisões a serem tomadas durante o jogo

QAV07 Achei que o Jogo de Empresas foi útil para o meu aprendizado

QAV06 Usar Jogos de Empresas melhora a eficácia do meu aprendizado

QAV10 As instruções fornecidas durante a aplicação do Jogo de Empresas foram relevantes

QAV05 Usar Jogos de Empresas torna o meu aprendizado mais produtivo

QAV08 As instruções fornecidas durante a aplicação do Jogo de Empresas foram completas

QAV11

As instruções fornecidas durante a aplicação do Jogo de Empresas foram precisas

QAV04 Usar Jogos de Empresas melhora o meu desempenho acadêmico

QAV02 Minha interação com o Jogo de Empresas foi clara e compreensivel

QAV09 As instruções fornecidas durante a aplicação do Jogo de Empresas foram de fácil compreensão

QAV01 Eu achei o Jogo de Empresas fácil de usar

QAV03 Interagir com Jogo de Empresas não requereu muito esforço mental
Butzke Dados da

(2015) pesquisa

\begin{tabular}{|c|c|}
\hline - & $67,42 \%$ \\
\hline- & $66,29 \%$ \\
\hline - & $64,03 \%$ \\
\hline - & $62,90 \%$ \\
\hline $52,73 \%$ & $59,66 \%$ \\
\hline- & $58,95 \%$ \\
\hline- & $57,20 \%$ \\
\hline - & $53,67 \%$ \\
\hline - & $53,30 \%$ \\
\hline $50,00 \%$ & $50,67 \%$ \\
\hline $50,00 \%$ & $47,73 \%$ \\
\hline $39,89 \%$ & $46,21 \%$ \\
\hline $49,45 \%$ & $46,14 \%$ \\
\hline $36,61 \%$ & $40,53 \%$ \\
\hline $35,79 \%$ & $37,10 \%$ \\
\hline $46,45 \%$ & $36,35 \%$ \\
\hline $17,76 \%$ & $25,99 \%$ \\
\hline $24,59 \%$ & $25,19 \%$ \\
\hline $10,11 \%$ & $20,53 \%$ \\
\hline$-14,21 \%$ & $-21,21 \%$ \\
\hline
\end{tabular}

Nota: Dados da pesquisa

As variáveis com piores escores na pesquisa obtiveram percentual na faixa de $20 \%$ a 30\% de concordância: "Eu achei o Jogo de Empresas fácil de usar" (QAV01: 20,53\%), "As instruções fornecidas durante a aplicação do Jogo de Em- 
presas foram de fácil compreensão" (QAV09: 25,19\%); "Minha interação com o Jogo de Empresas foi clara e compreensível" (QAV02: 25,99\%). Entretanto, a variável "Interagir com Jogo de Empresas não requereu muito esforço mental" (QAV03: $-18,63 \%$ ) apresentou o escore negativo. A baixa área de impacto nessas variáveis (QAV01, QAV02 e QAV03) comprova o estudo de Butzke (2015), no qual observou a menor pontuação dessas variáveis com a complexidade retratada nos jogos. Essa tendência nos resultados é confirmada também no discurso dos discentes participantes do Focus Group:

\footnotetext{
Eu achei que no começo foi bem complexo sobre o sistema [...] (Participante LF/2) Eu também achei um pouco difícil assim até no começo conversei com ele (professor) [...] (Participante IN/2)

Eu acho que o software poderia ser um pouco complexo no início só que isso se expõe a gente do que é realidade hoje quando você vai trabalhar numa empresa você tem que aprender tudo do zero e o material também era complexo [...] (Participante AF/2)

Eu achei que o layout em si ele e fácil bem intuitivo mais como funciona a temática do jogo e que é difícil de pegar o layout não [...] (Participante SM/1)
}

Essas declarações acentuam a dificuldade sentida pelos discentes participantes da pesquisa ao utilizar os Jogos de Empresas como ambiente de aprendizagem. Segundo suas percepções, a plataforma virtual, na qual os jogos estão hospedados, não se mostrou favorável ao uso no primeiro momento.

Por intermédio dos resultados mostrados na tabela 3, verifica-se que os discentes avaliaram o ambiente virtual de aprendizagem como favorável à aprendizagem, mantendo os impactos médios maiores que o ponto médio (4) da escala Likert aplicada nesta pesquisa. Porém, ao analisar os dados da tabela, verifica-se que nenhuma variável atinge $60 \%$ de concordância entre os discentes pesquisados. $A$ variável "As instruções fornecidas durante a aplicação do Jogo de Empresas eram atualizadas" (QAV12) é a única que obteve maior concordância nos dois estudos, nesta pesquisa, com 59,66\%, e em Butzke (2015), com 52,73\%.

Com relação aos piores resultados, nota-se que os resultados desta pesquisa corroboram o estudo de Butzke (2015) ao obter percentual abaixo de $30 \%$ nas variáveis: "Minha interação com o Jogo de Empresas foi clara e compreensível" (QAV02), "As instruções fornecidas durante a aplicação do Jogo de Empresas foram de fácil compreensão" (QAV09), "Eu achei o Jogo de Empresas fácil de usar" 
(QAV01) e "Interagir com Jogo de Empresas não requereu muito esforço mental" (QAV03). Porém, o estudo de Butzke (2015) apresentou os percentuais da área de impacto inferiores a este estudo. O jogo aplicado no estudo de Butzke (2015) foi um experimento específico para a pesquisa, e neste estudo foram utilizados jogos existentes no mercado a mais de 25 anos. Esse resultado evidencia que apesar deste jogo apresentar maior clareza nas informações, os discentes não perceberam esta qualidade ao utilizá-lo.

$\mathrm{Na}$ percepção dos discentes, a estratégia de ensino jogos de empresas foi considerada benéfica ao seu aprendizado, enquanto o ambiente de aprendizagem foi apontado como um pouco complexo. Para os discentes, a plataforma virtual, na qual os jogos estão hospedados, não se mostrou favorável ao uso no primeiro momento. Desse modo, é preciso considerar os aspectos que podem ter desmotivado os discentes no ambiente durante o seu processo de aprendizado e repensar o modo de utilização da plataforma virtual nos jogos de empresas.

$\mathrm{Na}$ análise fatorial (Tabela 4), para indicar os fatores resultantes da percepção dos discentes sobre a Skill acquisition nos jogos de empresas, onze variáveis (SKA01, SKA05, SKA06, SKA07, SKA11, SKA12, SKA13, SKA15, SKA16, SKA22, SKA30) foram excluídas durante o processo por apresentarem carga fatorial inferior a 0,55. Foram gerados na análise cinco fatores: Fator 1- Perspectiva sobre gestão (F1PG), Fator 2- Trabalho em equipe (F2TE), Fator 3- Obtenção de conhecimento (F3OC), Fator 4- Resolução de problemas (F4RP), Fator 5- Atitudes e habilidades (F5AH). Todos os 5 fatores tiveram autovalor acima de 1, Alfa de Cronbach superiores a 0,6 e a variância total explicada é de $72,36 \%$.

Quanto ao ambiente de aprendizagem (Tabela 4), o resultado da análise fatorial confirmou as categorias do instrumento de pesquisa elaborado nos estudos de Davis (1989), Delone e Mclean (2003), Ramos et al. (2013) e Butzke (2015). Portanto, os fatores foram definidos da seguinte forma: Fator 1- Qualidade da informação (F1QI); Fator 2- Utilidade percebida (F2UP); e Fator 3- Facilidade de uso (F3FU). Esses 3 fatores apresentaram autovalor acima de 1, Alfa de Cronbach superior a 0,06 e a variância total explicada de $76,33 \%$. 
Tabela 3 Análise fatorial

\begin{tabular}{|c|c|c|c|c|c|c|c|c|c|c|c|c|}
\hline \multicolumn{6}{|c|}{ Skill acquisition nos jogos de empresas } & \multicolumn{4}{|c|}{ Ambiente de aprendizagem } & \multicolumn{3}{|c|}{$\begin{array}{l}\text { Prática reflexiva e } \\
\text { atuação do professor }\end{array}$} \\
\hline \multirow{2}{*}{ Variáveis } & \multicolumn{5}{|c|}{ Fatores } & \multirow{2}{*}{ Var. } & \multicolumn{3}{|c|}{ Fatores } & \multirow{2}{*}{ Var. } & \multicolumn{2}{|c|}{ Fatores } \\
\hline & F1PG & F2TE & F3OC & F4RP & F5AH & & F1QI & F2UP & $\mathrm{F} 3 \mathrm{FU}$ & & F1RP & F2AP \\
\hline SKA25 & 0,832 & & & & & QAV11 & 0,838 & & & QAV19 & 0,829 & \\
\hline SKA26 & 0,775 & & & & & QAV09 & 0,816 & & & QAV18 & 0,816 & \\
\hline SKA24 & 0,76 & & & & & QAV10 & 0,807 & & & QAV20 & 0,797 & \\
\hline SKA27 & 0,747 & & & & & QAV08 & 0,748 & & & QAV17 & 0,66 & \\
\hline SKA28 & 0,714 & & & & & QAV12 & 0,694 & & & QAV16 & 0,634 & \\
\hline SKA29 & 0,697 & & & & & QAV05 & & 0,919 & & QAV14 & & 0,901 \\
\hline SKA23 & 0,62 & & & & & QAV06 & & 0,904 & & QAV15 & & 0,866 \\
\hline SKA19 & & 0,825 & & & & QAV04 & & 0,85 & & QAV13 & & 0,835 \\
\hline SKA1 8 & & 0,813 & & & & QAV07 & & 0,797 & & & & \\
\hline SKA20 & & 0,691 & & & & QAV03 & & & 0,824 & & & \\
\hline SKA21 & & 0,591 & & & & QAV01 & & & 0,658 & & & \\
\hline SKA03 & & & 0,792 & & & QAV02 & & & 0,544 & & & \\
\hline SKA04 & & & 0,788 & & & & & & & & & \\
\hline SKA02 & & & 0,707 & & & & & & & & & \\
\hline SKA09 & & & & 0,805 & & & & & & & & \\
\hline SKAl0 & & & & 0,718 & & & & & & & & \\
\hline SKA08 & & & & 0,687 & & & & & & & & \\
\hline SKA17 & & & & & 0,75 & & & & & & & \\
\hline SKAl4 & & & & & 0,696 & & & & & & & \\
\hline $\begin{array}{c}\text { Alfa de } \\
\text { Cronbach }\end{array}$ & 0,9116 & 0,8256 & 0,8153 & 0,7718 & 0,6896 & & 0,8906 & 0,933 & 0,6979 & & 0,8584 & 0,8708 \\
\hline AutoValor & 8,7184 & 1,4874 & 1,3802 & 1,1269 & 1,0352 & & \begin{tabular}{|l|}
6,5352 \\
\end{tabular} & 1,4217 & 1,2021 & & \begin{tabular}{|l|}
4,3483 \\
\end{tabular} & 1,3691 \\
\hline$\%$ Var & 45,89 & 7,83 & 7,26 & 5,93 & 5,45 & & 54,46 & 11,85 & 10,02 & & \begin{tabular}{|l|}
36,79 \\
\end{tabular} & 34,68 \\
\hline$\%$ Acum. & 45,89 & 53,72 & 60,98 & 66,91 & 72,36 & & 54,46 & \begin{tabular}{|l|}
66,31 \\
\end{tabular} & 76,33 & & 36,79 & 71,47 \\
\hline
\end{tabular}

Fonte: Dados da pesquisa.

Com o resultado da análise fatorial da prática reflexiva e atuação do professor, também foram confirmadas as categorias do instrumento de pesquisa realizado nos estudos de Ramos et al. (2013) e Araújo (2014). O Fator 1 - Reflexão na prática (F1RP) e Fator 2 - Atuação do professor (F2AP) apresentaram autovalores acima de 1, Alfa de Cronbach superior a 0,8 e a variância total explicada de 71,47\%. Durante este processo de análise, não houve necessidade de excluir variáveis, porque todas tiveram carga fatorial superior a 0,55. 


\section{Considerações finais}

O presente artigo contribui com as pesquisas na área de ensino em Administração, especialmente com a adoção do Jogos de Empresas como estratégia de ensino ativa num ambiente virtual de aprendizagem. Ao analisar a percepção dos discentes ao utilizar a estratégia de ensino jogos de empresas em um ambiente virtual de aprendizagem, os resultados apontam que os discentes tiveram uma percepção positiva sobre o uso da estratégia de ensino Jogos de empresas e no ambiente de aprendizagem sentiram um pouco de dificuldades ao utilizar a plataforma digital dos jogos.

Os discentes percebem o uso da estratégia Jogos de Empresas como benéfica ao seu aprendizado nos seguintes aspectos: (1) Integrando a aprendizagem em diversas áreas; (2) Estimulando a criatividade; (3) Contribuindo para a análise de um problema sob diversos pontos de vista com a discussão em grupo; (4) Motivando o trabalho em equipes e (5) Ampliando a visão sobre o funcionamento de uma empresa. O primeiro aspecto foi destaque também nos estudos de Chang (2003), Chang et al. (2005), Neves e Alberton (2017) e Butzke e Alberton (2017), tal como o segundo e o quinto aspectos se destacaram no estudo de Butzke e Alberton (2017).

Enquanto o ambiente de aprendizagem foi apontado como um pouco complexo pelos discentes. Na percepção dos discentes, a plataforma virtual se mostrou desfavorável para o uso no primeiro momento. Em vista disso, é necessário considerar os aspectos que podem ter desmotivado os discentes no ambiente durante o seu processo de aprendizado e repensar o modo de utilização da plataforma virtual nos jogos de empresas. Porém, um fato interessante é que o jogo e o ambiente utilizado neste estudo estão a mais de 25 anos presentes no mercado.

Portanto, os resultados apresentados permitem concluir que os jogos de empresas têm contribuído para o desenvolvimento do exercício coletivo dos discentes, através da sua capacidade de desenvolver o trabalho em equipe, ao propor ao discente a experiência de lidar com visões distintas sobre uma questão. Bem como, o seu envolvimento ativo no processo de aprendizagem, transformando-o em criador de seu conhecimento (SIGNORI et al., 2018). Porém, para adotar a estratégia de ensino, os docentes precisam estar atentos se a mesma atende seus planos de aula. 
O estudo apresenta contribuições relevantes ao campo. Uma delas refere-se à apresentação de evidências que corroboram que a adoção de jogos de empresas no processo de aprendizagem proporciona a integração de conteúdo de diversas áreas do conhecimento (SAUAIA; ZERRENNER, 2009; MOTTA; QUINTELLA, 2012; CHANG et al., 2014; NEVES; ALBERTON, 2017). Outra contribuição teórica trata-se de que os jogos têm favorecido o desenvolvimento do exercício coletivo e a lidar com visões diferentes, entendendo que cada indivíduo parte de uma perspectiva (MADKUR; MIRTVI; LOPES, 2008; MOTTA; QUINTELLA, 2012; NEVES; ALBERTON, 2017). Quanto a implicação prática do estudo, a estratégia de ensino ativa jogo de empresas precisa continuar sendo aplicada a equipes de discentes pelos docentes, para proporcionar o compartilhamento de conhecimento dos discentes e o seu trabalho em equipe.

Neste sentido, o artigo contribuiu com o fornecimento de subsídios aos docentes para aperfeiçoar o processo de ensino-aprendizagem, ao abordar a percepção dos discentes sobre o uso da estratégia de ensino ativa Jogos de empresas e o seu ambiente de aprendizagem. Com os aspectos "contribuindo para a análise de um problema sob diversos pontos de vista com a discussão em grupo" e "motivando o trabalho em equipes", os docentes podem trabalhar com a formação de equipes mais heterogêneas possíveis, pois isso promoverá maiores debates e a compreensão de outras perspectivas por parte dos discentes. Entretanto, no contexto atual da educação superior, divido ao COVID-19, onde grande parte dos discentes estão tendo aulas remotas, questiona-se como os docentes estão adotando os jogos de empresas e outras estratégias de ensino ativa pelo ambiente virtual de aprendizagem.

A dificuldade de acesso a turmas que utilizam essa estratégia de ensino ativa deve ser considerada como uma limitação desta pesquisa, pois poucas turmas estavam utilizando a estratégia de ensino ativa Jogos de empresas, inclusive em um dos campus de uma universidade ainda não existe um espaço apropriado para a aplicação da estratégia com os discentes. Além disso, a falta de atenção dos participantes também dificultou a execução da pesquisa, uma vez que houve muitos discentes que deixaram algumas questões da pesquisa em branco, e ainda quem respondeu de modo equivocado, o que contribuiu para a diminuição do tamanho da amostra esperada inicialmente no estudo. 
Este estudo também mostrou que é necessário aprofundar a investigação sobre o ambiente virtual de aprendizagem, para melhor compreender o motivo pelo qual os discentes consideraram um pouco complexo o seu uso. Bem como, ampliar o tamanho da amostra, com discentes dos cursos da área de gestão. Para pesquisas futuras, sugere-se também a continuidade deste estudo, com aplicação dos instrumentos em outras regiões do país, com outras amostras de discentes, a fim de observar se compartilham desta percepção com relação à estratégia de ensino Jogos de Empresas.

A aplicação de experimentos em pesquisa neste âmbito também pode ser um caminho para a coleta de dados, ao abordar os temas em discussão. Sugere-se ainda aprofundar o conhecimento nesta perspectiva para conferir a validade educacional da estratégia e do ambiente ao processo de aprendizagem dos discentes com a utilização de estilos de aprendizagem e decisão e a experiência discente. Estudos futuros também podem abordar as estratégias de ensino, em especial os jogos de empresas na educação remota e/ou educação a distância, investigando como os docentes têm adaptado essas estratégias para atual momento vivido pelo ensino.

\section{Agradecimento}

Este trabalho foi realizado com o apoio da Coordenação de Aperfeiçoamento de Pessoal de Nível Superior - Brasil (CAPES), através do Programa de Suporte à Pós-Graduação de Instituições de Ensino Comunitárias (PROSUC), de acordo com a Portaria CAPES n. 149/2017.

\section{Referências}

ADOBOR, H.; DANESFAR, A. Management simulations: determining their effectiveness. Journal of Management Development, v. 25, n. 2, p. 151-168, fev. 2006. DOI: https://doi.org/10.1108/02621710610645135 BARDIN, L. Análise de Conteúdo (1a ed.). São Paulo: Edições 70, 2016.

BHATTARAI, S.; MAHARJAN, S. Determining the Factors Affecting on Digital Learning Adoption among the Students in Kathmandu Valley: An Application of Technology Acceptance Model (TAM). International 
Journal of Engineering and Management Research, v. 10, n. 3, p. 131-141, Jun. 2020. DOI: https://doi. org/10.31033/ijemr.10.3.20

BERGAMASCHI FILHO, E.; ALBURQUERQUE, A. A. Um estudo sobre as atitudes tomadas durante um jogo de empresas aplicado em uma turma de graduação em contabilidade e seu impacto na tomada de decisão. Revista de Contabilidade do Mestrado em Ciências Contábeis da UERJ, v. 15, n. 2, p. 19-31, maio/ago. 2010.

BUIL, I.; CATALÁN, S.; MARTíNEZ, E. Encouraging intrinsic motivation in management training: The use of business simulation games. The International Journal of Management Education, v. 17, n. 2, p. 162171, Jul. 2019. DOI: https://doi.org/10.1016/j.ijme.2019.02.002

BUTZKE, M. A.; ALBERTON, A. Estilos de aprendizagem e jogos de empresa: a percepção discente sobre estratégia de ensino e ambiente de aprendizagem. Revista de Gestão, v. 24, n. 1, p. 72-84, jan/mar. 2017. DOI: https://doi.org/10.1016/j.rege.2016.10.003

BUTZKE, M. A. (2015). Jogos de Empresa baseados em simulação e aprendizagem ativa: analisando a tomada de decisão em processos logísticos. 2015. 173 f. Tese (Doutorado em Administração e Turismo) Programa de pós-graduação em Administração e Turismo, Universidade do Vale do Itajaí, Biguaçu, 2015. CALIARI, K. V. Z.; ZILBER, M. A.; PEREZ, G. Tecnologias da informação e comunicação como inovação no ensino superior presencial: uma análise das variáveis que influenciam na sua adoção. Revista de gestão, v. 24, n.1, p. 247-255, Jun/ set. 2017. DOI: https://doi.org/10.1016/j.rege.2017.05.003

CARVALHO, L. M. C.; PEREIRA, J. M. DO F.; DIAS, R. M. T. S.; NORONHA, A. B. Estilos de aprendizagem dos alunos de administração: Um estudo empírico aplicado em Instituições de Ensino Superior Portuguesas. Administração: Ensino e Pesquisa, v. 21, n. 3, p. 348-384, set. 2020.

CARVALHO NETO, S.; TAKAOKA, H. Ambientes virtuais de aprendizagem de código livre como apoio ao ensino presencial na área de ciências sociais aplicadas: um estudo de caso em uma instituição de ensino superior. In: ENCONTRO DA ASSOCIAÇÃO NACIONAL DE PÓS-GRADUAÇÃO E PESQUISA EM ADMINISTRAÇÃO, 33, 2009, São Paulo. Anais... São Paulo: Anpad, 2009.

CARVALHO NETO, S.; TAKAOKA, H. Dimensões de qualidade em ambientes virtuais de aprendizagem: estudos de um modelo de relações entre qualidade da informação e do sistema, satisfação, uso e benefícios percebidos por meio de aplicação de modelagem de equações estruturais. In: ENCONTRO DA ASSOCIAÇÃO NACIONAL DE PÓS-GRADUAÇÃO E PESQUISA EM ADMINISTRAÇÃO, 34, 2010, Rio de Janeiro. Anais... São Paulo: Anpad, 2010.

CHANG, J. Use of business simulation games in Hong Kong. Simulation \& gaming, v. 34, n. 3, p. 358-366, set. 2003. DOI: https://doi.org/10.1177/1046878103255876

CHANG, J.; JENNINGS, D.; TO, C. K. M.; SUN, L. Strategic management: Na evaluation of the use of three learning methods in China. In: DEVELOPMENTS IN BUSINESS SIMULATION \& EXPERIENTIAL EXERCISES, 32, 2005.

CHANG, J.; MOON, K. K. L; LAU, M. M.; WONG, M. C. Students' View on the Use of Business Gaming In: Hong Kong-An Update. In: DEVELOPMENTS IN BUSINESS SIMULATION AND EXPERIENTIAL LEARNING: PROCEEDINGS OF THE ANNUAL ABSEL CONFERENCE, 41, 2014.

DAVIS, F. D. Perceived usefulness, perceived ease of use, and user acceptance of information technology. Management Information Systems Quarterly, v. 13, n. 3, p. 319-340, set. 1989. DOI: https://doi. org/10.2307/249008 
DELONE, W. H.; MCLEAN, E. R. The DeLone e McLean Model of Information System Success: A Ten-Year Update. Journal of Management Information Systems, v. 19, n. 4, p.9-30, 2003. DOI: https://doi.or $\mathrm{g} / 10.1080 / 07421222.2003 .11045748$

FARASHAHI, M.; TAJEDDIN, M. Effectiveness of teaching methods in business education: A comparison study on the learning outcomes of lectures, case studies and simulations. The International Journal of Management Education, v. 16, n. 1, p. 131-142, 2018. DOI: 10.1016/j.ijme.2018.01.003

FERREIRA, J. B.; FREITAS, A. S.; SILVA, J. F.; SILVA, M. A. S.; GIOVANNINI, C. J. Efeitos moderadores do gênero sobre fatores que afetam a intenção de uso de e-learning no Ensino Superior. In: Encontro Da Associação Nacional De Pós-Graduação E Pesquisa Em Administração, 37, 2013, Rio de Janeiro. Anais... São Paulo: Anpad, 2013.

FREITAS, A. S.; FERREIRA, J. B.; AMARAL, M.; GIOVANNINI, C. J. Intenção de Uso de E-learning no Ensino Superior: Há diferenças de Percepção entre Homens e Mulheres? Revista de Administração e Inovação, v. 12, n. 1, p. 70-97, 2015.

GUNDALA, R. R.; SINGH, M. Role of simulations in student learning: A case study using marketing simulation. Journal of Educational Research and Innovation, v. 5, n. 2, p. 1-14, 2016.

HEMZO, M. A.; LEPSCH, S. L. Jogos de empresas com foco em marketing estratégico: uma análise fatorial da percepção dos participantes. Revista Brasileira de Gestão de Negócios, v. 8, n. 20, p. 23-33, jan/ abr. 2006.

HUANG, F.; SÁNCHEZ-PRIETO, J. C.; TEO, T., GARCÍA-PEÑALVO, F. J.; SÁNCHEZ, E. M. T.; ZHAO, $C$. The influence of university students' learning beliefs on their intentions to use mobile technologies in learning: a study in China and Spain. Educational Technology Research and Development, v. 68, p. 35473565, jul. 2020. DOI: https://doi.org/10.1007/s11423-020-09806-0

JENNINGS, D.R. Strategic management: an evaluation of the use of three learning methods. The Journal of Management Development, v. 21, n. 9, p. 655-665, nov. 2002. DOI: https://doi. org/10.1108/02621710210441658

LIAO, Y.; HUANG, Y.; WANG, Y. Factors affecting students' continued usage intention toward business simulation games: an empirical study. Journal of Educational Computing Research, v. 53, n. 2, p. 260283, ago. 2015.

LIN, Chung-Yu; HUANG, Chung-Kai; KO, Chao-Jung. The impact of perceived enjoyment on team effectiveness and individual learning in a blended learning business course: The mediating effect of knowledge sharing. Australasian Journal of Educational Technology, v. 36, n. 1, p. 126-141, 2020.

LÖFFLER, A. PRIFTI, L.; LEVKOVSKYI, B.; UTESCH, M.; KRCMAR, H. Simulation games for the digital transformation of business processes: Development and application of two prototypes from the automotive and online retail sector. In: 2018 IEEE Global Engineering Education Conference (EDUCON). IEEE, 2018. p. 1475-1483.

LOPES, P. C. (2001). Formação de Administradores: uma abordagem estrutural e técnico-didática. 2001. 221 f. Tese (Doutorado em Engenharia de Produção) - Programa de pós-graduação em Engenharia de Produção, Universidade Federal de Santa Catarina, Florianópolis, 2001.

MADKUR, F. N.; MRTVI, V. DE O.; LOPES, P. C. Estilos de aprendizagem e constituição de equipes: um estudo no contexto dos jogos de empresas. In: ENCONTRO DA ASSOCIAÇÃO NACIONAL DE 
PÓS-GRADUAÇÃO E PESQUISA EM ADMINISTRAÇÃO, 32, 2008, Rio de Janeiro. Anais... São Paulo: Anpad, 2008.

MILES, W. G.; BIGGS, W. D.; SCHUBERT, J. N. Student perceptions of skill acquisition through cases and a general management simulation, a comparison. Simulation and Gaming, v. 17, n. 1, p. 7-24, mar. 1986. DOI: https://doi.org/10.1177/0037550086171002

MONDINI, V. E. D.; BORGES, G. R.; FLORIANI, R.; DOMINGUES, M. J. C. S.; LAVARDA, C. E. F. A Relação entre Qualidade, Benefícios e Satisfação na Intenção do Uso de AVA por Parte de Alunos de Graduação a Distância. Revista Meta: Avaliação, v. 8, n. 22, p. 69-91, jan/ abr. 2016.

MOTTA, G. S.; QUINTELLA, R. H. A utilização de jogos e simulações de empresas nos cursos de graduação em administração no estado da Bahia. Revista Eletrônica de Administração, v. 18, n. 2, p. 317-338, mai/ ago. 2012. DOI: https://doi.org/10.1590/S1413-23112012000200002

MOTTA, G. S.; MELO, D. R. A.; PAIXÃO, R. B. O jogo de empresas no processo de aprendizagem em administração: o discurso coletivo de alunos. Revista de administração contemporânea, v. 16, n. 3, p. 342-359, mai/jun. 2012. DOI: https://doi.org/10.1590/S1415-65552012000300002

MRTVI, V. O.; WESTPHAL, F. K.; MELO, R. B.; FELDMANN, P. R. Jogos de Empresas: Abordagens ao Fenômeno, Perspectivas Teóricas e Metodológicas. Revista de Administração Contemporânea, v. 21, n. 1, p. 19-40, jan/ feb. 2017. DOI: https://doi.org/10.1590/1982-7849rac2017150212

MULBERT, A. L.; BRAZ JUNIOR, O. O. Interações espontâneas em ambiente virtual de aprendizagem por meio de dispositivos móveis: um mapeamento baseado na análise de registros de acesso ao sistema. Revista eletrônica de Sistemas de Informação, v. 16, n. 2, v. 15, n. 2, mai/ ago. 2016. DOI:10.21529/ RESI.2016.1502003

NEVES, F.S; ALBERTON, A. Jogos de empresas: o que os alunos aprendem? Um estudo com alunos de graduação e pós-graduação. In: ENCONTRO DA ASSOCIAÇÃO NACIONAL DE PÓS-GRADUAÇÃO E PESQUISA EM ADMINISTRAÇÃO, 41, 2017, São Paulo. Anais... São Paulo: Anpad, 2017.

OLIVEIRA, M. A.; MELO, N. H. DA S. Jogo de empresas e mercado de ações: uma análise do aprendizado dos alunos em um curso de Administração. Administração: Ensino e Pesquisa, v. 21, n. 3, p. 316-347, set. 2020.

PEREIRA, A. T. C.; SCHMITT, V.; DIAS, M. R. Á. AVA-Ambientes Virtuais de Aprendizagem em Diferentes Contextos. Rio de Janeiro: Editora Ciência Moderna Ltda, 2007.

PEREIRA, F. A. M.; OLIVEIRA, E.; MOMO, D. C. Fatores determinantes da satisfação de estudantes em um curso de administração à distância. Conhecimento Interativo, v. 7, n. 1, p. 75-87, jan/ jun. 2013.

PEREIRA, F. A.; RAMOS, A. S. M.; CHAGAS, M. M. Satisfação e continuidade de uso em um ambiente virtual de aprendizagem. Revista de Gestão, v. 22, n. 1, p. 133-153, jan/ mar. 2015. DOI: https://doi. org/10.5700/rege555

PEREIRA, J. C. R. Análise de Dados Qualitativos: estratégias metodológicas para ciências da saúde, humanas e sociais. São Paulo: EDUSP, 2004.

PEREIRA, L. S. Método do Caso para o Ensino em Administração. 2012. 126 f. Dissertação (Mestrado em Administração) - Programa de pós-graduação em Administração e Turismo, Universidade do Vale do Itajaí, Biguaçu, 2012.

RAMOS, A. S. M.; SILVA, J. E.; CARVALHO, M. L. A. Fatores que influenciam o uso de um ambiente virtual de aprendizagem por alunos de administração na modalidade a distância. In: ENCONTRO DA 
ASSOCIAÇÃO NACIONAL DE PÓS-GRADUAÇÃO E PESQUISA EM ADMINISTRAÇÃO, 37, 2013, Rio de Janeiro. Anais... São Paulo: Anpad, 2013.

SAUAIA, A. C. A.; ZERRENNER, S. A. Jogos de Empresas e Economia Experimental: um Estudo da Racionalidade Organizacional na Tomada de Decisão. Revista de Administração Contemporânea, v. 13, n. 2, p. 189-209, abr/jun. 2009. DOI: https://doi.org/10.1590/S1415-65552009000200003

SEDDON, P. B.; KIEW, M. A. Partial test and development of Deloneand MCLean's Model of IS Success. Academic Journal of Interdisciplinary Studies, v. 4, n. 1, p. 90-109, nov. 1996. https://doi.org/10.3127/ ajis.v4i1.379

SIGNORI, G. G.; GUIMARÃES, J. C. F. D.; SEVERO, E. A.; ROTTA, C. Gamification as an innovative method in the processes of learning in higher education institutions. International Journal of Innovation and Learning, v. 24, n. 2, p. 115-137, 2018.

SILVA, A. B.; LIMA, T. B.; SONAGLIO, A. L. B.; GODOI, C. K. Dimensões de um sistema de aprendizagem em ação para o ensino de administração. Administração: ensino e pesquisa, v. 13, n. 1, p. 9-46, jan/ mar. 2012. DOI: https://doi.org/10.13058/raep.2012.v13n1.97

SILVA, A. M.; SAUAIA, A. C. A. Jogo de empresas como ambiente laboratorial para pesquisas econômicas. Ensaios FEE, v. 38, n. 4, p. 931-958, mar. 2018.

SILVA, Anielson Barbosa. Action Learning: Lecturers, Learners, and Managers at the Center of Management Education in Brazil. In: Human Centered Management in Executive Education. Palgrave Macmillan, London, 2016. p. 209-221.

TEIXEIRA, G.; STEFANO, S. R.; CAMPOS, E. A. R. E-learning, percepções sobre satisfação no treinamento a distância em instituição financeira: reação versus impacto. Revista de Administração, Contabilidade e Economia, v. 14, n. 1, p. 225-250, jan/ abr. 2014. DOI: https://doi.org/10.18593/race.v14i1.4735 VENKATESH, V.; DAVIS D. A. Theoretical Extension of the Technology Acceptance Model: Four Longitudinal Field Studies. Management Science, v. 46, n. 2, p. 186-204, fev. 2000. DOI: https://doi.org/10.1287/ mnsc.46.2.186.11926

YAKUBU, M. N.; MUHAMMADOU, K. A. H. Nigerian Instructors' Acceptance of Learning Management Systems: A Structural Modeling Approach. In: 2020 IST-Africa Conference (IST-Africa), 2020, Kampala. Anais... Kampala: IST-Africa, 2020.

ZULFIQAR, S.; SARWAR, B.; AZIZ, S.; CHANDIA, K. E.; KHAN, M. K. An Analysis of Influence of Business Simulation Games on Business School Students' Attitude and Intention Toward Entrepreneurial Activities. Journal of Educational Computing Research, v. 57, n. 1, p. 1-25, 2018. DOI: https://doi. org/10.1177/0735633117746746 


\section{Apêndice A}

Figura com os Instrumentos de Skill acquisition e de Ambiente Virtual de Aprendizagem e Prática Reflexiva

Instrumento de Skill acquisition: SKA01:Proporciona novos conhecimentos sobre a operação de uma empresa; SKA02:Proporciona maior aprofundamento do conteúdo em relação a outras metodologias de ensino; SKA03:Auxilia na aquisição de informações; SKA04:Ajuda a conservar as informações ao longo prazo; SKA05:Ajuda a integrar a aprendizagem em diversas áreas: Contabilidade, Finanças, Marketing etc; SKA06:Aumenta a capacidade de identificar os problemas gerenciais; SKA07:Favorece à análise de um problema sob diferentes pontos de vista, na discussão do grupo; SKA08:Aumenta a compreensão para usar as informações na resolução de problemas; SKA09:Auxilia a tomar decisões baseadas em informações incompletas; SKA10:Aumenta a confiança na habilidade para resolver problemas práticos; SKA11:Aumenta a competência para o planejamento das operações de negócios; SKA12:Aumenta a capacidade para implementar suas ideias e planos; SKA13: Auxilia na revisão de políticas e práticas organizacionais; SKA14:Aumenta a sua confiança na habilidade de trabalhar independentemente; SKA15:Aumenta a consciência sobre suas atitudes administrativas; SKA16:Aumenta a consciência sobre as atitudes dos colegas; SKA17:Auxilia a lidar com a insegurança; SKA18:Aumenta a capacidade de comunicação com os seus colegas; SKA19:Aumenta a habilidade de fornecer informações para os colegas; SKA20:Aumenta sua eficácia como participante na resolução de problemas em grupo; SKA21:Motiva o trabalho em grupo; SKA22:Ajuda na resolução de conflitos; SKA23:Proporciona experimentar um comportamento que conhecia e ainda não havia vivenciado; SKA24:Propicia a adoção de novos comportamentos administrativos; SKA25:Amplia a sua visão de gestor sobre o funcionamento de uma empresa; SKA26:Permite aprender algo sobre você como gerente; SKA27:Ajuda a associar a teoria à pratica gerencial; SKA28:Agrega realismo organizacional ao ensino; SKA29:Ajuda a esclarecer as atividades pertinentes à prática profissional; SKA30:Estimula a criatividade. 
Instrumentos de Ambiente Virtual de Aprendizagem e Prática Reflexiva: QAV01:Eu achei o jogo de empresas fácil de usar; QAV02:Minha interação com o jogo de empresas foi clara e compreensível; QAV03:Interagir com jogo de empresas não requereu muito esforço mental; QAV04:Usar jogos de empresas melhora o meu desempenho acadêmico; QAV05:Usar jogos de empresas torna o meu aprendizado mais produtivo; QAV06:Usar jogos de empresas melhora a eficácia do meu aprendizado; QAV07:Achei que o jogo de empresa foi útil para o meu aprendizado; QAV08:As instruções fornecidas durante a aplicação do jogo de empresas foram completas; QAV09:As instruções fornecidas durante a aplicação do jogo de empresas foram de fácil compreensão; QAV10:As instruções fornecidas durante a aplicação do jogo de empresas foram relevantes; QAV11:As instruções fornecidas durante a aplicação do jogo de empresas foram precisas; QAV12:As instruções fornecidas durante a aplicação do jogo de empresas eram atualizadas; QAV13:O professor estimula constantemente o uso da plataforma; QAV14:O professor dá apoio continuo no esclarecimento de dúvidas de conteúdo; QAV15:O professor fornece sistematicamente informações das atividades do jogo de empresas; QAV16:Percebi oportunidades de alterar a minha visão sobre as decisões a serem tomadas durante o jogo; QAV17:Percebi a existência de visões diferentes sobre as decisões a serem tomadas durante o jogo; QAV18:Compreendi que minhas experiências poderiam favorecer o entendimento sobre o problema e meIhorar as decisões a serem tomadas durante o jogo; QAV19:Percebi que a minha decisão poderia ter impactos que não havia percebido, e por isso, alterei a minha visão sobre as decisões a serem tomadas durante o jogo; QAV20:Ao expor a minha decisão, percebi que poderia mudar o meu posicionamento de forma a melhorá-lo. 